\title{
Mortality trends from diabetes mellitus in the seven socioeconomic regions of Mexico, 2000-2007
}

\author{
Juan Jesús Sánchez-Barriga1
}

Suggested citation

Sánchez-Barriga JJ. Mortality trends from diabetes mellitus in the seven socioeconomic regions of Mexico, 2000-2007. Rev Panam Salud Publica 2010;28(5):368-75.

ABSTRACT Objective. To determine trends in mortality from diabetes mellitus nationwide according to federative entity, socioeconomic region, and sex and to establish the association between education level, federation entity of residence, and socioeconomic region and mortality from diabetes in Mexico during the years 2000-2007.

Methods. Records of mortality associated with diabetes for 2000-2007 were obtained from the National Information System of the Secretariat of Health. This information is generated by the National Institute of Statistics, Geography and Informatics through death certificates. Codes of International Classification of Diseases, 10th Revision, that correspond to the basic cause of death from diabetes mellitus were identified. Rates of mortality by federative entity and socioeconomic region were calculated, along with the strength of association (obtained by Poisson regression) between federative entity of residence, socioeconomic region, and education level and mortality from diabetes. The seven socioeconomic regions elaborated by the National Institute of Statistics, Geography and Informatics include the 32 federative entities according to indicators related to well-being such as education, occupation, health, housing, and employment. Results. Individuals who did not complete elementary school had a higher risk of dying from diabetes (relative risk [RR] 2.104, 95\% confidence interval [CI] 2.089-2.119). The federative entity and socioeconomic region with the strongest association with mortality from diabetes were Mexico City (RR 2.5, CI 2.33-2.68 for 2000; RR 2.06, CI 1.95-2.18 for 2007) and region 7 (RR 2.47, CI 2.36-2.57 for 2000; RR 2.05, CI 1.98-2.13 for 2007).

Conclusions. Mortality rates increased from 77.9 to 89.2 per 100000 inhabitants in the period 2000-2007. Women had higher mortality than men. Individuals who did not complete elementary school had a higher risk of dying from diabetes (RR 2.104, CI 2.089-2.119). Mexico City as federative entity and socioeconomic region 7 presented the strongest association with mortality from diabetes.

Key words Diabetes mellitus; mortality; social class; Mexico.

The World Health Organization estimates that around 57 million people died in 2002 worldwide; 998000 of them died of diabetes (1). This disease ranked 12 th as a cause of mortality, with $1.9 \%$ of

\footnotetext{
1 Direction of Operative Research in Epidemiology, General Direction of Epidemiology, Secretariat of Health, México, D.F. Send correspondence to: Juan Jesús Sánchez-Barriga, jsanchez@dgepi.salud.gob.mx
}

deaths, and it is expected to rank seventh worldwide by the year 2030, accounting for $3.3 \%$ of deaths (2). The International Diabetes Federation has estimated that the number of individuals with diabetes will increase from 284.6 million in 2010 to 438.4 million in 2030 (3).

In 2000, there were 339035 deaths due to diabetes in Latin America and the Caribbean, which represented a loss of
757096 years of productive life among persons under 65 years of age and an expenditure of more than US\$3 000 million. Permanent disability caused a loss of 12699087 years and of more than US\$50 000 million, and temporary disability caused a loss of 136701 years in the active population and roughly US\$763 million. The estimated annual cost of diabetes in Latin America and the 
Caribbean is approximately US\$65 216 million (4).

In Mexico, diabetes has a very high economic cost because of the high prevalence of the disease. In relation to expenditure on diabetes in 2009, an increase of $33 \%$ is expected by 2011 . The total expenditure projected for that year is US\$778 427475 . This amount includes direct costs (US\$343 226541 ) and indirect costs (US\$435 200 934) (5).

In Mexico, 52\% (US\$162 252503 ) of medical expenses for the management of diabetes is covered by the individual, $3 \%$ is covered by private medical insurance (US\$9 360714 ), while 45\% is covered by the government. Of each US $\$ 100$ spent in Mexico for treating diabetes, there is a US\$55 benefit to $10 \%$ of the population covered by the private sector, while US\$45 is used to provide medical attention to $90 \%$ of the population. The aforementioned shows a great disparity in medical attention for diabetics in Mexico. This deficient medical attention leads to complications and consequently the disability and premature death of these subjects (6).

Diabetes reduces life expectancy and is associated with few years of healthy life. In Mexico, it has been observed that subjects 50 and 80 years of age have a decreased life expectancy of 10 and 4 years, respectively. On the other hand, life expectancy without disability in diabetics at the age of 50 was 20.8 years and in nondiabetics was 29.9 years (7).

In other countries like the United States of America (U.S.), diabetes ranked sixth as the main cause of death in the year 2000 with 69301 deaths (8). By the year 2005, the U.S. had 75119 deaths due to diabetes (9). In 2007, 17.5 million diabetics were identified, and the cost of diabetes for the U.S. health system was $\$ 174$ billion dollars (10).

In Mexico, the problem is even more serious as mortality has increased since 1940; the rise has been substantial in the last four decades and in recent years it is the first cause of mortality in the Mexican population (11). This increase in mortality from diabetes could be related to the epidemiologic transition in Mexico, which is characterized by a gradual substitution of deaths due to communicable causes for a pattern in which chronic degenerative diseases prevail $(12,13)$. This epidemiologic transition has yielded a greater life expectancy, which in turn causes increased economic development, better social organization, and industrialization (14).

Another factor that could be related to the high mortality from diabetes in Mexico, is the increased availability of processed food, which has conditioned a rise in calories consumed, derived mainly from carbohydrates, as well as a remarkable decrease in physical activity, causing an increase in the body mass index $(11,15,16)$. All these factors plus the genetic load for diabetes present in the Mexican population (17) could be contributing to the important rise in the morbidity and mortality due to this disease.

Diabetes represents an impact on the Mexican Health System, as it ranks 11th among the main reasons for hospitalization. Also, the average length of hospital stay for the diabetic patient is greater than for patients with other diseases (6.1 versus 3.5 days); in addition, it is the second cause of in-hospital mortality (11). Forty-two percent of diabetic patients die before the age of 64 years. It is a frequent cause for seeking medical attention and in 2002 was the 10th reason for medical consultation; furthermore, after having the disease for some time, patients exhibit complications related to macro- and microangiopathy such as ischemic cardiopathy, cerebral vascular disease, renal insufficiency, and blindness among others; these complications cause disability, leading individuals to an early retirement (18-20).

Because of the importance of diabetes in Mexico, it was decided to determine the rates of mortality nationwide, by federative entity, and by socioeconomic region as well as the predominant sex. Also, it was decided to establish the strength of the association between education level, federative entity of residence, and socioeconomic region and mortality from diabetes in the period 2000-2007.

\section{METHODS}

The records of mortality associated with diabetes for 2000-2007 were obtained from the National Information System of the Secretariat of Health. This information is generated by the National Institute of Statistics, Geography and Informatics and is collected from death certificates issued nationwide (21). All records of mortality in which the basic cause of death was diabetes mellitus in the period 2000-2007 were included in the study; therefore, the codes of International Classification of Diseases, 10th Revision (ICD-10) (22) were identified. They corresponded to the basic cause of death from diabetes such as (E10 insulindependent diabetes mellitus, E11 diabetes mellitus non-insulin-dependent, E12 diabetes mellitus associated to malnutrition, E13 other specified diabetes mellitus, and E14 nonspecified diabetes mellitus).

Age-adjusted mortality rates nationwide (23) per 100000 inhabitants-with the world population as the standard (24) —were obtained. The age-adjusted mortality rates per 100000 inhabitants from each federative entity and from each of the seven socioeconomic regions (Table 1) established by the National Institute of Statistics, Geography and Informatics, were obtained (25). The national population estimated by the National Population Council for 2000-2007 $(26,27)$ was used for the rate adjustment; the relative risk (RR) and 95\% confidence interval (CI) for each of the seven socioeconomic regions and each federative entity of residence, with mortality from diabetes by Poisson regression, were calculated.

The seven socioeconomic regions of Mexico originate at the National Insti-

TABLE 1. Socioeconomic regions of Mexico

\begin{tabular}{cl}
\hline $\begin{array}{c}\text { Socioeconomic } \\
\text { region }\end{array}$ & \multicolumn{1}{c}{ Federative entities } \\
\hline 1 & Chiapas, Guerrero, Oaxaca \\
2 & Campeche, Hidalgo, Puebla, San Luis Potosí, Tabasco, Veracruz \\
3 & Durango, Guanajuato, Michoacán, Tlaxcala, Zacatecas \\
4 & Colima, México, Morelos, Nayarit, Querétaro, Quintana Roo, Sinaloa, \\
5 & Yucatán \\
6 & Baja California, Baja California Sur, Chihuahua, Sonora, Tamaulipas \\
7 & Aguascalientes, Coahuila, Jalisco, Nuevo León \\
\hline
\end{tabular}

Source: National Institute of Statistics, Geography and Informatics of Mexico. 
tute of Statistics, Geography and Informatics, where the differences observed in the social and economic conditions of the population throughout Mexico are presented according to the XII General Census on Population and Housing. The seven socioeconomic regions comprise the 32 federative entities according to indicators related to well-being such as education, occupation, health, housing, and employment. The federative entities classified in the same region have similar characteristics on average- that is, they are homogenous-while the regions differ from one another. Region 7 shows the entities with the most favorable conditions according to the indicators considered. Region 1 includes entities with less favorable conditions.

The methodology used to establish the regions had the objective of forming strata with minimal variance in an attempt to group the elements that were more alike or closer to one another, following a criterion of established similarity, which allows for differentiating one region from another. Among the techniques used are Mahalonobis distances and a combination of factorial analysis and the algorithm of the K-means (25).

The Poisson regression model was chosen to determine the force of association between federative entities, socioeconomic regions of residence, and education level with mortality from diabetes because, as a dependent variable, the number of deaths has a Poisson distribution that takes positive whole values. Poisson regression is equivalent to a logarithmic regression of mortality rates. The exponential coefficients allow for estimation of the RR of dying (28).

All registrations were handled by the Access 2003 informatic program; all data were then transferred to the Number Cruncher Statistical System program (NCSS) 2001, by which the force of association between each federative entity and socioeconomic region of residence and mortality from diabetes was obtained by means of Poisson regression (29). The Epidat version 3.1 program was used to determine the age-adjusted mortality rates by federative entity and socioeconomic region.

\section{RESULTS}

From 2000 to 2007, 477036 individuals died of diabetes mellitus in Mexico. During that time, the mortality rate obtained

TABLE 2. Mortality from diabetes mellitus by gender, Mexico, 2000-2007

\begin{tabular}{ccccc}
\hline Year of death & No. & Standardized rate & Men $^{\mathrm{a}}$ & Women $^{\mathrm{a}}$ \\
\hline 2000 & 46656 & 77.9 & 75.3 & 80.0 \\
2001 & 49904 & 80.3 & 77.6 & 82.2 \\
2002 & 54780 & 85.1 & 84.1 & 85.7 \\
2003 & 59205 & 88.8 & 86.7 & 90.2 \\
2004 & 62043 & 89.6 & 88.2 & 90.4 \\
2005 & 67102 & 93.4 & 92.8 & 93.5 \\
2006 & 68159 & 91.4 & 92.1 & 90.4 \\
2007 & 69187 & 89.2 & 91.1 & 87.3 \\
\hline
\end{tabular}

a Rate per 100000 inhabitants standardized by the direct method using the standard world population.

TABLE 3. Relative risk (RR) of dying from diabetes mellitus according to education level, and $95 \%$ confidence interval $(\mathrm{Cl})$ according to Poisson regression, Mexico, 2000-2007

\begin{tabular}{lcc}
\hline \multicolumn{1}{c}{ Education level } & $\mathrm{RR}$ & $\mathrm{Cl}$ \\
\hline No school & 1 & $\mathrm{~N} / \mathrm{A}$ \\
Incomplete elementary & 2.104 & $2.089-2.119$ \\
Complete elementary & 0.470 & $0.465-0.475$ \\
High school or equivalent & 0.263 & $0.260-0.266$ \\
Senior in high school or equivalent & 0.145 & $0.142-0.147$ \\
College & 0.184 & $0.181-0.186$ \\
\hline
\end{tabular}

Note: N/A: not applicable.

by the direct method standardized with the world population, increased significantly from 77.9 in 2000 to 89.2 in 2007. Women predominated (Table 2).

With Poisson regression, the strength of association between education level and death from diabetes was determined. Also, it was determined that individuals who did not complete elementary school had a higher risk of dying from diabetes (RR 2.104, CI 2.089-2.119), whereas subjects with a higher education level had a lower risk of dying as is the case for those with a college education (RR 0.184, CI 0.181-0.186) (Table 3).

During the period 2000-2007, the adjusted mortality rates in the federative entity tended to increase. Coahuila and Mexico City presented the highest mortality. In 2000 and 2007, the mortality rates per 100000 for these entities were 61.6, CI 58.4-64.8; 80.5, CI 77-84.1; 63.2, CI 61.6-64.7; 80.4, CI 78.7-82.1, respectively.

The states with the lowest mortality were Guerrero and Quintana Roo. In 2000 and 2007, the mortality rates per 100000 for these entities were 30.4, CI 28.4-32.4; 46.4, CI 44-48.8; 24.9, CI 20.5-29.2; 50.7, CI 45.4-56 (Table 4).

The socioeconomic region with the highest mortality in the study was number 7 . In 2000 and 2007, the mortality rates per 100000 observed in this region were 63.2, CI 61.6-64.7 and 80.4, CI 78.7-82.1, respectively.

The region with the lowest mortality was number 1 in 2000 and 2007. The mortality rates per 100000 observed for this region were 31.8, CI 30.7-32.9 and 48.6, CI 47.3-49.9 (Table 5).

The strength of association between each federative entity of residence with death from diabetes in the period 20002007 was determined by Poisson regression, taking Guerrero as reference, which is one of the three states less economically favored and which, along with Oaxaca and Chiapas make up region 1. The entities with the strongest association were Mexico City and Coahuila. In 2000 and 2007, the strength of association for these entities was RR 2.5, CI 2.33-2.68; RR 2.06, CI 1.95-2.18; RR 2.04, CI 1.88-2.22; and RR 1.65, CI 1.55-1.77; respectively (Table 6).

The federative entities with the lowest association with mortality from diabetes were Quintana Roo and Chiapas. The strength of association for these entities in 2000 and 2007 was RR 0.54, CI 0.45-0.64; RR 0.7, CI 0.63-0.78; RR 0.91, CI 0.83-0.99; and 0.86, CI 0.81-0.92 (Table 6).

Also, the strength of association between each socioeconomic region of residence and death from diabetes mellitus was determined by Poisson regression, 
TABLE 4. Age-adjusted mortality rate and $95 \%$ confidence interval $(\mathrm{Cl})$ by federative entity of residence of individuals who died from diabetes mellitus, Mexico, 2000-2007

\begin{tabular}{|c|c|c|c|c|c|c|}
\hline \multirow[b]{2}{*}{ Federative entity } & \multicolumn{2}{|c|}{2000} & \multicolumn{2}{|c|}{2004} & \multicolumn{2}{|c|}{2007} \\
\hline & Mortality rate ${ }^{a}$ & $\mathrm{Cl}$ & Mortality rate & $\mathrm{Cl}$ & Mortality rate & $\mathrm{Cl}$ \\
\hline Aguascalientes & 45.6 & $41.1-50.0$ & 60.6 & $55.6-65.6$ & 68.2 & $63.0-73.4$ \\
\hline Baja California & 54.6 & $51.4-57.9$ & 61.0 & $57.8-64.3$ & 62.6 & $59.4-65.7$ \\
\hline Baja California Sur & 46.6 & $39.7-53.5$ & 53.8 & $46.7-60.9$ & 53.0 & $46.2-59.8$ \\
\hline Campeche & 30.8 & $26.6-35.1$ & 44.4 & $39.4-49.3$ & 58.2 & $52.6-63.8$ \\
\hline Coahuila & 61.6 & $58.4-64.8$ & 79.2 & $75.6-82.8$ & 80.5 & $77.0-84.1$ \\
\hline Colima & 41.7 & $36.2-47.1$ & 56.5 & $50.3-62.6$ & 61.9 & $55.6-68.3$ \\
\hline Chiapas & 33.3 & $31.3-35.3$ & 41.0 & $38.8-43.1$ & 48.8 & $46.5-51.1$ \\
\hline Chihuahua & 47.1 & $44.6-49.6$ & 60.0 & $57.3-62.7$ & 68.7 & $65.8-71.5$ \\
\hline Durango & 42.9 & $39.6-46.2$ & 55.6 & $51.9-59.3$ & 65.5 & $61.5-69.5$ \\
\hline Guanajuato & 55.1 & $53.0-57.2$ & 70.2 & $67.8-72.5$ & 77.1 & $74.7-79.6$ \\
\hline Guerrero & 30.4 & $28.4-32.4$ & 41.4 & $39.1-43.7$ & 46.4 & $44.0-48.8$ \\
\hline Hidalgo & 39.7 & $37.1-42.2$ & 48.6 & $45.8-51.4$ & 58.0 & $55.0-61.0$ \\
\hline Jalisco & 48.3 & $46.7-50.0$ & 61.3 & $59.4-63.1$ & 62.5 & $60.7-64.4$ \\
\hline Mexico & 55.8 & $54.4-57.2$ & 68.6 & $67.1-70.1$ & 76.0 & $74.4-77.5$ \\
\hline Mexico City & 63.2 & $61.6-64.7$ & 75.5 & $73.8-77.1$ & 80.4 & $78.7-82.1$ \\
\hline Michoacán & 45.8 & $43.8-47.9$ & 58.7 & $56.4-60.9$ & 64.6 & $62.2-67.0$ \\
\hline Morelos & 45.3 & $42.1-48.6$ & 57.5 & $54.0-61.1$ & 63.4 & $59.7-67.1$ \\
\hline Nayarit & 37.0 & $33.3-40.7$ & 46.6 & $42.4-50.7$ & 51.8 & $47.5-56.1$ \\
\hline Nuevo León & 40.9 & $38.9-42.9$ & 54.8 & $52.5-57.0$ & 60.1 & $57.7-62.4$ \\
\hline Oaxaca & 32.4 & $30.5-34.2$ & 46.2 & $44.1-48.4$ & 51.2 & $48.9-53.5$ \\
\hline Puebla & 51.6 & $49.7-53.6$ & 68.5 & $66.3-70.7$ & 71.3 & $69.0-73.5$ \\
\hline Querétaro & 47.9 & $44.1-51.7$ & 54.6 & $50.7-58.5$ & 61.8 & $57.7-65.8$ \\
\hline Quintana Roo & 24.9 & $20.5-29.2$ & 42.6 & $37.4-47.7$ & 50.7 & $45.4-56.0$ \\
\hline San Luis Potosí & 37.9 & $35.5-40.4$ & 48.3 & $45.6-51.0$ & 55.3 & $52.4-58.2$ \\
\hline Sinaloa & 38.5 & $36.1-40.9$ & 50.0 & $47.3-52.7$ & 44.3 & $41.8-46.7$ \\
\hline Sonora & 46.0 & $43.2-48.8$ & 58.1 & $55.0-61.1$ & 59.3 & $56.2-62.3$ \\
\hline Tabasco & 44.5 & $41.3-47.7$ & 66.7 & $62.9-70.6$ & 68.9 & $65.0-72.7$ \\
\hline Tamaulipas & 51.3 & $48.7-53.9$ & 62.3 & $59.5-65.1$ & 63.2 & $60.4-65.9$ \\
\hline Tlaxcala & 54.5 & $50.0-59.1$ & 66.5 & $61.6-71.5$ & 73.6 & $68.4-78.7$ \\
\hline Veracruz & 45.5 & $44.0-47.1$ & 59.7 & $58.0-61.5$ & 67.2 & $65.4-69.0$ \\
\hline Yucatán & 33.4 & $30.8-36.0$ & 47.4 & $44.3-50.4$ & 52.8 & $49.7-56.0$ \\
\hline Zacatecas & 35.0 & $32.0-38.0$ & 48.2 & $44.8-51.7$ & 57.0 & $53.2-60.8$ \\
\hline
\end{tabular}

a Rate per 100000 inhabitants adjusted by the direct method using the national population as the standard population.

TABLE 5. Age-adjusted mortality rate and $95 \%$ confidence intervals $(\mathrm{Cl})$ by socioeconomic region of individuals who died from diabetes mellitus, Mexico, 2000-2007

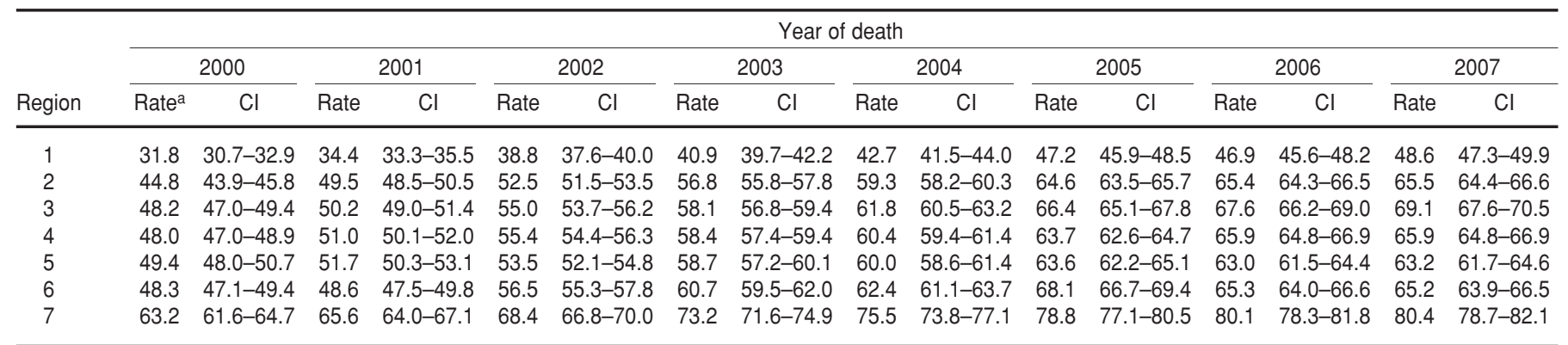

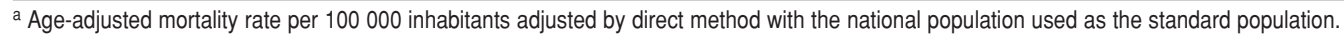

taking as reference region 1, observing that region 7 presented the strongest association. In 2000 and 2007, the strengths of association for this region were RR 2.47, CI 2.36-2.57 and RR 2.05, CI 1.982.13 , respectively. Regions $2-6$ presented a strength of association similar to but lower than that of region 7 (Table 7).

There were 1985 registries eliminated from the analyzed information; 664 were eliminated because age was omitted and 1321 died before the year 2000-although the death certificate was elaborated in the period 2000-2007.

\section{DISCUSSION}

Diabetes mellitus is a disease that has increased remarkably in the last decades. In the year 2000 the standardized mor- tality rate per 100000 inhabitants was 77.9 and it increased significantly over the following years to reach a rate of 89.2 in 2007 (Table 2). Mortality from diabetes possibly will continue with a rising trend, because according to the estimations of morbidity for diabetes in the adult population in the period 19952025 , there will be an increase of $35 \%$ in the prevalence worldwide. In developed 
TABLE 6. Relative risk (RR) of dying from diabetes mellitus by federative entity of residence and $95 \%$ confidence interval (Cl), according to Poisson regression, Mexico, 2000-2007

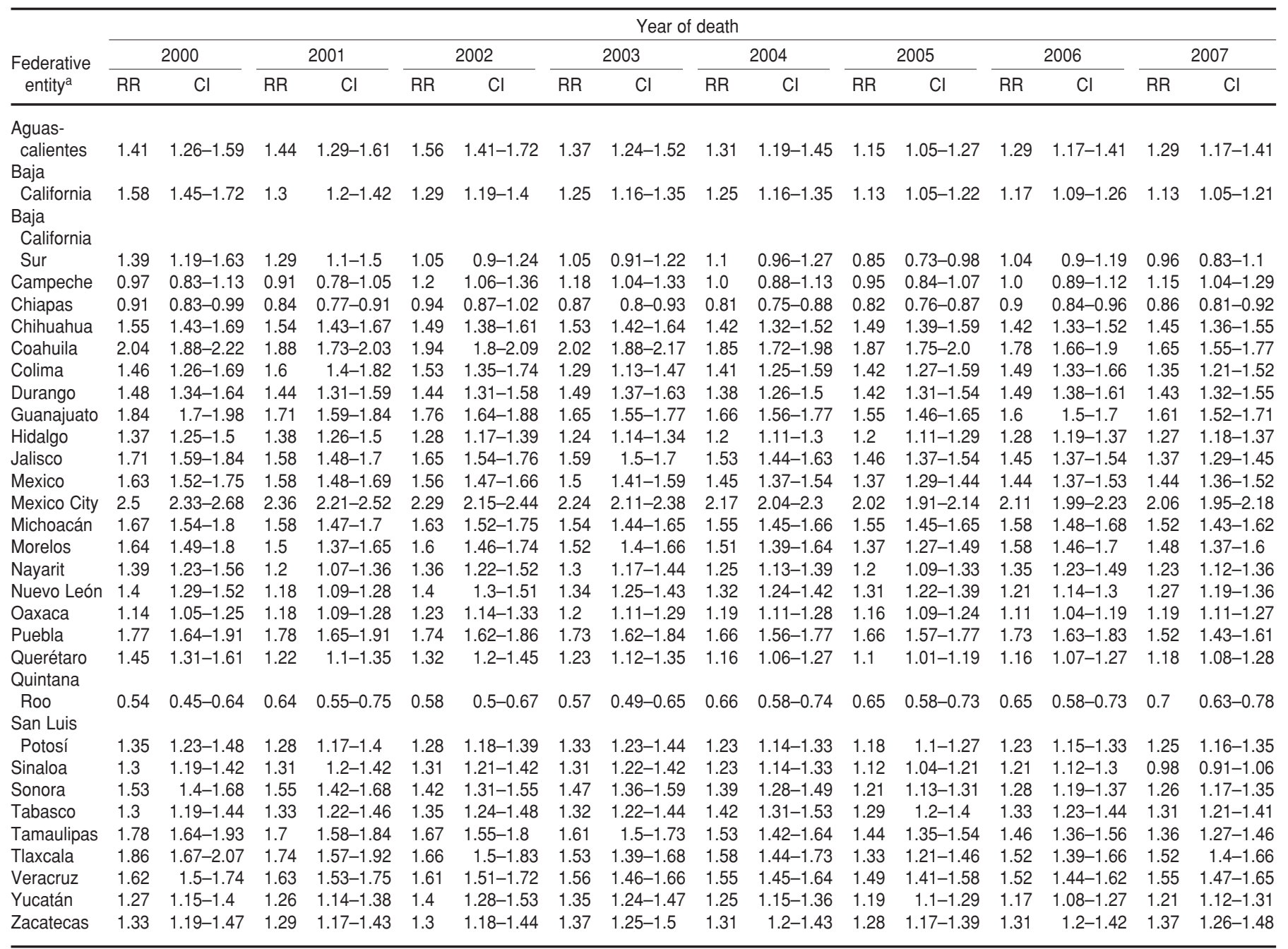

a The state of Guerrero was taken as reference value for analysis of Poisson regression.

TABLE 7. Relative risk (RR) of dying from diabetes mellitus by region and $95 \%$ confidence interval (Cl) according to Poisson regression, Mexico, 2000-2007

\begin{tabular}{|c|c|c|c|c|c|c|c|c|c|c|c|c|c|c|c|c|}
\hline \multirow[b]{3}{*}{ Regiona } & \multicolumn{16}{|c|}{ Year of death } \\
\hline & \multicolumn{2}{|r|}{2000} & \multicolumn{2}{|r|}{2001} & \multicolumn{2}{|r|}{2002} & \multicolumn{2}{|r|}{2003} & \multicolumn{2}{|r|}{2004} & \multicolumn{2}{|r|}{2005} & \multicolumn{2}{|r|}{2006} & \multicolumn{2}{|r|}{2007} \\
\hline & $\mathrm{RR}$ & $\mathrm{Cl}$ & $\mathrm{RR}$ & $\mathrm{Cl}$ & $\mathrm{RR}$ & $\mathrm{Cl}$ & $\mathrm{RR}$ & $\mathrm{Cl}$ & $\mathrm{RR}$ & $\mathrm{Cl}$ & $\mathrm{RR}$ & $\mathrm{Cl}$ & $\mathrm{RR}$ & $\mathrm{Cl}$ & $\mathrm{RR}$ & $\mathrm{Cl}$ \\
\hline 3 & 1.67 & $1.6-1.74$ & 1.6 & $1.53-1.66$ & 1.54 & $1.49-1.6$ & 1.54 & $1.48-1.6$ & 1.57 & $1.51-1.62$ & 1.52 & $1.47-1.57$ & 1.55 & $1.5-1.6$ & 1.52 & $1.47-1.57$ \\
\hline 4 & 1.48 & $1.42-1.54$ & 1.44 & $1.39-1.5$ & 1.39 & $1.34-1.44$ & 1.38 & $1.33-1.43$ & 1.37 & $1.32-1.41$ & 1.3 & $1.26-1.34$ & 1.35 & $1.31-1.4$ & 1.31 & $1.27-1.35$ \\
\hline 5 & 1.58 & $1.52-1.66$ & 1.52 & $1.46-1.59$ & 1.39 & $1.33-1.44$ & 1.44 & $1.38-1.49$ & 1.4 & $1.35-1.46$ & 1.34 & $1.29-1.39$ & 1.33 & $1.28-1.38$ & 1.29 & $1.24-1.33$ \\
\hline 6 & 1.64 & $1.57-1.71$ & 1.51 & $1.45-1.57$ & 1.54 & $1.48-1.6$ & 1.56 & $1.5-1.62$ & 1.53 & $1.47-1.58$ & 1.49 & $1.44-1.54$ & 1.43 & $1.39-1.48$ & 1.38 & $1.33-1.42$ \\
\hline
\end{tabular}

a Region 1 was taken as reference value for analysis of Poisson regression.

countries, the increase will be $27 \%$, and in underdeveloped countries it will be $48 \%$. The projected number of Mexican diabetics by the year 2025 is approximately 11.7 million (30).
In Mexico, there were 477036 deaths from diabetes in the period 2000-2007. Mortality was higher in women than in men (Table 2). Similar results have been observed in other studies, with is- chemic cardiopathy being the cause of death in a high percentage of the assessed population (19).

The risk of dying from diabetes mellitus was higher in subjects who did not 
complete elementary school (RR 2.104, CI 2.089-2.119) (Table 3). Education level is a socioeconomic indicator of health (31); lower education level is associated with a higher risk of getting sick (32). Gnavi et al. (33) noted that among individuals who died of type 2 diabetes 4756 $(71.2 \%)$ were illiterate or had attended only elementary school, $1290(19.3 \%)$ attended high school, and $627(9.3 \%)$ attended college.

During the period of study, mortality rates increased significantly (Table 2). However, there exists the possibility that mortality from diabetes was underreported in this study, because, among other factors, diabetes is a chronic disease that is associated with other illnesses such as cardiovascular disease, which can be more evident and therefore registered as the basic cause of death (34, 35). Studies carried out in the U.S. have found a frequency of underreporting diabetes as the principal cause of death of up to $35 \%$ (36). In Mexico, in the period 1999-2001, an underreporting of deaths of $13.7 \%$ was identified (37). Murray et al. (38) performed a study with the goal of improving the comparability of mortality statistics from diabetes between Mexico and the U.S. and identified a high possibility (RR 1.87, CI 1.81-1.92, $P<0.001)$ that in Mexico diabetic individuals who did not die in a hospital were given a death certificate with cardiovascular disease listed as the cause of death. Thus, it is possible that diabetes mortality reported in this study could be even higher.

In the period of the study, region 7, which corresponds to Mexico City, presented one of the highest mortality rates and the strongest association with mortality from diabetes (Tables 5 and 7). Mexico City has one of the highest incidences of this disease among the most important cities in Latin America and the Caribbean (39). The Health and Nutrition National Survey showed that the urban population has a higher prevalence of obesity than rural ones, and Mexico City was one of the federative entities with the highest obesity rates among the adult population in the northern states of Mexico (40).

Obesity is the main risk factor for developing type 2 diabetes, with a $61 \%$ prevalence (41). According to the classification by socioeconomic regions of the
National Institute of Statistics, Geography and Informatics, Mexico City has the best economic situation (Table 1) as a result of technological innovations and changes. Some of these changes reduce people's physical activity and alter their eating habits (42), which could lead to obesity and therefore to increased morbidity and mortality from diabetes. Among men and women, a high prevalence of overweight $(41.3 \%$ and $36.3 \%$, respectively) and obesity $(19.4 \%$ and $29 \%$, respectively) has been identified in Mexico. Both are related to an increased prevalence of diabetes mellitus and arterial hypertension (43).

Other studies have shown that Mexico City has one of the highest mortality rates from diabetes in Mexico. Barquera et al. (44) performed a study with the objective of analyzing the tendencies of mortality from diabetes in Mexico from 1980 to 2000 and considered four regions: north, center, south, and Mexico City. They found 582826 deaths from diabetes with a high proportion of women (56\%). Mexico City and the center region had the highest age-adjusted mortality rates of the four regions: 76.6-82.1 and 42-78 per 100000 inhabitants, respectively. However, other studies have revealed that in Mexico City, subjects with diabetes have a longer life expectancy (4.5 years) than in other large cities in Latin America and the Caribbean (39).

Guerrero and Quintana Roo showed the lowest adjusted rates (Table 4) and a weaker association with mortality from diabetes (Table 6). It has been reported that these entities have a low prevalence of obesity, which could account for the low mortality there (45). Other studies have reported a low mortality in southern federative entities, mainly Quintana Roo (44).

The states with greater well-being according to the classification by socioeconomic regions of the National Institute of Statistics, Geography and Informatics (Table 1) comprise those in regions 7 and 6. Of them, the former showed the highest adjusted rates (Table 5) and the strongest association with mortality from diabetes (Table 7), whereas the states that comprise regions 2-6 presented a similar strength of association with mortality from diabetes but lower than in region 7 , also exhibiting lower age-adjusted mortality rates.
Mexico has regions in different stages of the process of epidemiologic transition (46) and also has great disparities with regard to health services (6), education, employment, and personal income. The preceding factors could bear on mortality from diabetes in Mexico $(33,47)$.

This study observed that mortality from diabetes in Mexico is high, with a tendency to increase. Mexico City as a federative entity and socioeconomic region 7 presented the highest mortality rates in Mexico and the highest risk of dying from this disease in the period of study. Thus, it is important to emphasize preventive measures such as healthy nutrition and physical activity. It is also necessary to improve medical attention in order to detect diabetes promptly as well as to treat complications in an efficient way, with the aim of improving the quality of life of these subjects and diminishing mortality. The foregoing could be achieved by applying multisectoral programs in which the main participants are health and education institutions that promote healthy nutrition, adequate physical activity, and maintaining a healthy weight.

It would also be necessary to apply government measures aimed at regulating the media as far as unhealthy food is concerned as well as at promoting physical activity, preventing development of the disease in the groups at risk, and improving glucose control in individuals at risk and in those already sick with the disease.

The limitations of this study are that ICD-10 does not have a category for diabetes and cardiovascular disease for which the mortality and the strength of association among some federative entities and socioeconomic regions in Mexico reported in this paper could be even higher.

\section{CONCLUSIONS}

In Mexico, mortality rates from diabetes increased from 77.9 to 89.2 per 100000 in the period 2000-2007. Women had higher mortality than men. Individuals who did not complete elementary school had a higher risk of dying from diabetes ( $R R$ 2.104, CI 2.089-2.119). Mexico City as federative entity and socioeconomic region 7 presented the strongest association with mortality from diabetes. 


\section{REFERENCES}

1. World Health Organization. A report on world health 2004, changing history. Geneva: WHO; 2004. Available from: http://www. who.int/whr/2004/en/report04_en.pdf. Accessed 13 October 2009.

2. World Health Organization. World health statistics 2008. Geneva: WHO; 2008. Available from: http://www.who.int/whosis/whostat/ EN_WHS08_Full.pdf. Accessed 10 November 2009.

3. IDF diabetes atlas, 4 th ed. Brussels, Belgium: International Diabetes Federation; 2009. Available from: http://www.diabetesatlas. org/content/prevalence-estimates-diabetesmellitus-dm-2010 and http://www.diabetes atlas.org/content/prevalence-estimatesdiabetes-mellitus-dm-2030. Accessed 28 June 2010.

4. Barcelo A, Aedo C, Rajpathak S, Robles S. The cost of diabetes in Latin America and the Caribbean. Bull World Health Organ. 2003; 81(1):19-27.

5. Arredondo A, de Icaza E. Financial requirements for the treatment of diabetes in Latin America: implications for the health system and for patients in Mexico. Diabetologia. 2009;52(8):1693-5.

6. Arredondo A, Barcelo A. The economic burden of out-of-pocket medical expenditures for patients seeking diabetes care in Mexico. Diabetologia. 2007;50(11):2408-9.

7. Andrade FC. Measuring the impact of diabetes on life expectancy and disability-free life expectancy among older adults in Mexico. J Gerontol B Psychol Sci Soc Sci. 2010;65B(3): 381-9.

8. National Center for Chronic Disease Prevention and Health Promotion. National estimates on diabetes. Atlanta, GA: Centers for Disease Control and Prevention; 2003. Available from: http://www.cdc.gov/diabetes/ pubs/estimates.htm. Accessed 18 November 2009.

9. National Center for Health Statistics. Health, United States, 2008. Hyattsville, MD: NCHS; 2009. Available from: http://www.cdc.gov/ nchs/data/hus/hus08.pdf. Accessed 18 November 2009.

10. Economic costs of diabetes in the U.S. in 2007. Diabetes Care. 2008;31(3):596-615.

11. Rull JA, Aguilar-Salinas CA, Rojas R, RiosTorres JM, Gomez-Perez FJ, Olaiz G. Epidemiology of type 2 diabetes in Mexico. Arch Med Res. 2005;36(3):188-96.

12. Fernández P, Martínez D, Partida V. The demographic situation in Mexico. Twenty-five years of epidemiological transition in Mexico. Mexico, D.F.: National Population Council; 1999. Pp. 15-27. Available from: http://www. conapo.gob. $\mathrm{mx} /$ publicaciones $/ \mathrm{sdm} / \mathrm{sdm}$ 1999/99002.pdf. Accessed 2 November 2009.

13. Stevens G, Dias RH, Thomas KJ, Rivera JA, Carvalho N, Barquera S, et al. Characterizing the epidemiological transition in Mexico: national and subnational burden of diseases, injuries, and risk factors. PLoS Med. 2008;5(6): e125.

14. Yusuf S, Reddy S, Ounpuu S, Anand S. Global burden of cardiovascular diseases: part I: general considerations, the epidemiologic transition, risk factors, and impact of urbanization. Circulation. 2001;104(22):2746-53.
15. Rivera JA, Barquera S, Gonzalez-Cossio $T$ Olaiz G, Sepulveda J. Nutrition transition in Mexico and in other Latin American countries. Nutr Rev. 2004;62(7 Pt 2):S149-57.

16. Sanchez-Castillo CP, Pichardo-Ontiveros E, Lopez RP. Epidemiología de la obesidad. Gac Med Mex. 2004;140(Suppl 2):S3-20.

17. Lorenzo C, Serrano-Rios M, Martinez-Larrad MT, Gabriel R, Williams K, GonzalezVillalpando C, et al. Was the historic contribution of Spain to the Mexican gene pool partially responsible for the higher prevalence of type 2 diabetes in Mexican-origin populations? The Spanish Insulin Resistance Study Group, the San Antonio Heart Study, and the Mexico City Diabetes Study. Diabetes Care. 2001;24(12):2059-64.

18. Khaw AV, Kessler C. Epidemiologie, Risikofaktoren und Genetik. Haemostaseologie. 2006;26(4):287-97.

19. Huxley R, Barzi F, Woodward M. Excess risk of fatal coronary heart disease associated with diabetes in men and women: meta-analysis of 37 prospective cohort studies. BMJ. 2006; 332(7533):73-8

20. Johansen OE, Birkeland KI. Preventing macrovascular disease in patients with type 2 diabetes mellitus. Am J Cardiovasc Drugs. 2003;3(4):283-97.

21. Secretariat of Health. Mortality. Mexico, D.F.: Health Information National System; 2008. Available from: http://www.salud.gob.mx/ apps/htdocs/estadisticas/basesdedatos/ index.html. Accessed 1 October 2009.

22. World Health Organization. International statistical classification of diseases and problems related to health. Tenth review CIE10. Geneva: WHO; 1995.

23. Inskip H, Beral V, Fraser P, Haskey J. Methods for age-adjustment of rates. Stat Med. 1983; 2(4):455-66.

24. Ahmad OB, Boschi-Pinto C, Lopez AD, Murray CJL, Lozano R, Inoue M. Age standardization of rates: a new WHO standard. In: Global programme on evidence for health policy discussion paper. Series 31. Geneva: WHO; 1999. Pp. 1-12.

25. National Institute of Statistics, Geography and Informatics. Socioeconomic regions of Mexico. Mexico, D.F.: National Institute of Statistics, Geography and Informatics; 2000. Available from: http://jweb.inegi.org.mx/ niveles/datosnbi/reg_soc mexico.pdf. Accessed 20 July 2009.

26. Projections of the population of Mexico 2005-2050. Mexico, D.F.: Population National Council; 2006. Available from: http://www. conapo.gob. $\mathrm{mx} /$ index.php?option $=\mathrm{com}$ content\&view $=$ article\&id=36\& Itemid $=234$ Accessed 23 July 2009.

27. Annex to the sixth report of government 2006. Population projections and main features by state. In: Human and social development of Mexico, Fox V., ed. Mexico, D.F.: Secretariat of Governance; 2006. Pp. 14-22.

28. Cameron AC, Trivedi PK. Regression analysis of count data. Cambridge: Cambridge University Press; 1998.

29. Hintze J. Number cruncher statistical systems. Kaysville, Utah: NCSS and PASS; 2001.

30. King H, Aubert RE, Herman WH. Global burden of diabetes, 1995-2025: prevalence, nu- merical estimates, and projections. Diabetes Care. 1998;21(9):1414-31.

31. Rogot E, Sorlie PD, Johnson NJ, Schmitt C. Mortality study of 1.3 million persons by demographic, social, and economic factors: 1979-1985 follow-up. NIH Publication 923297:1-5. Bethesda, MD: National Institutes of Health; 1992.

32. Bachmann MO, Eachus J, Hopper CD, Davey Smith G, Propper C, Pearson NJ, et al. Socioeconomic inequalities in diabetes complications, control, attitudes and health service use: a cross-sectional study. Diabet Med. 2003; 20(11):921-9.

33. Gnavi R, Petrelli A, Demaria M, Spadea $T$, Carta Q, Costa G. Mortality and educational level among diabetic and non-diabetic population in the Turin Longitudinal Study: a 9-year follow-up. Int J Epidemiol. 2004;33(4): 864-71.

34. Fuller JH, Elford J, Goldblatt P, Adelstein AM. Diabetes mortality: new light on an underestimated public health problem. Diabetologia. 1983;24(5):336-41.

35. McEwen LN, Kim C, Haan M, Ghosh D, Lantz PM, Mangione CM, et al. Diabetes reporting as a cause of death: results from the Translating Research into Action for Diabetes (TRIAD) study. Diabetes Care. 2006;29(2):247-53.

36. Lu T-H, Anderson RN, Kawachi I. Trends in frequency of reporting improper diabetesrelated cause-of-death statements on death certificates, 1985-2005: an algorithm to identify incorrect causal sequences. Am J Epidemiol. 2010;171(10):1069-78.

37. Silvi J. On the estimation of mortality rates for countries of the Americas. Epidemiol Bull. 2003;24(4):1-5.

38. Murray CJ, Dias RH, Kulkarni SC, Lozano R, Stevens GA, Ezzati M. Improving the comparability of diabetes mortality statistics in the U.S. and Mexico. Diabetes Care. 2008;31(3): 451-8.

39. Andrade F. Estimating diabetes and diabetesfree life expectancy in Mexico and seven major cities in Latin America and the Caribbean. Rev Panam Salud Publica. 2009;26(1):9-16.

40. Shamah-Levy T, Villalpando-Hernandez S, Rivera-Dommarco JA. Results of nutrition from ENSANUT 2006. Cuernavaca, Mexico: National Institute of Public Health; 2007. Available from: http://www.insp.mx/ensanut/ resultados ensanut.pdf. Accessed 27 November 2009.

41. Wolf AM, Colditz GA. Current estimates of the economic cost of obesity in the United States. Obes Res. 1998;6(2):97-106.

42. Popkin BM. The shift in stages of the nutrition transition in the developing world differs from past experiences. Public Health Nutr. 2002;5(1A):205-14.

43. Sanchez-Castillo $\mathrm{CP}$, Velasquez-Monroy $\mathrm{O}$ Lara-Esqueda A, Berber A, Sepulveda J, Tapia-Conyer R, et al. Diabetes and hypertension increases in a society with abdominal obesity: results of the Mexican National Health Survey 2000. Public Health Nutr. 2005;8(1):53-60.

44. Barquera S, Tovar-Guzman V, CamposNonato I, Gonzalez-Villalpando C, RiveraDommarco J. Geography of diabetes mellitus mortality in Mexico: an epidemiologic transi- 
tion analysis. Arch Med Res. 2003;34(5): 407-14.

45. Velazquez-Monroy O, Rosas Peralta M, Lara Esqueda A, Pastelin Hernandez G, SanchezCastillo C, Attie F, et al. Prevalencia e interrelación de enfermedades crónicas no transmisibles y factores de riesgo cardiovascular en México. Resultados finales de la Encuesta Na- cional de Salud (ENSA) 2000. Arch Cardiol Mex. 2003;73(1):62-77.

46. Frenk J, Bobadilla JL, Sepúlveda J, Cervantes ML. Health transition in middle-income countries: new challenges for health care. Health Policy Plan. 1989;4(1):29-39.

47. McEwen LN, Kim C, Karter AJ, Haan MN, Ghosh D, Lantz PM, et al. Risk factors for mortality among patients with diabetes: the Translating Research into Action for Diabetes (TRIAD) Study. Diabetes Care. 2007;30(7): 1736-41.

Manuscript received on 9 February 2010. Revised version accepted for publication on 8 September 2010 .

RESUMEN Objetivo. Determinar las tendencias de mortalidad por diabetes mellitus en México, en función de cada entidad federativa, región socioeconómica y sexo, y establecer la relación entre el nivel de educación, la entidad federativa de residencia y la región socioeconómica, y la mortalidad por diabetes durante el período 2000-2007.

Tendencias de la mortalidad por diabetes mellitus en las siete regiones socioeconómicas de México, 2000-2007

Palabras clave
Métodos. Los datos de mortalidad asociada a la diabetes correspondientes a los años 2000 y 2007 se obtuvieron del Sistema Nacional de Información de la Secretaría de Salud; esta información es generada por el Instituto Nacional de Estadística y Geografía a partir de los certificados de defunción. Se determinaron los códigos de la Clasificación Internacional de Enfermedades, $10{ }^{a}{ }^{a}$ Revisión, que corresponden a la diabetes mellitus como principal causa de muerte. Se calculó la mortalidad por entidad federativa y región socioeconómica, junto con la fuerza de asociación (mediante la regresión de Poisson) entre la entidad federativa de residencia, la región socioeconómica y el nivel de educación, y la mortalidad por diabetes. El Instituto Nacional de Estadísticas y Geografía agrupa las 32 entidades federativas en siete regiones socioeconómicas conforme a los indicadores relativos al bienestar, tales como educación, ocupación, salud, vivienda y empleo.

Resultados. Las personas que no finalizaron la escuela primaria están expuestas a un riesgo mayor de morir por diabetes (riesgo relativo [RR] 2 104; intervalo de confianza de 95\% [IC] 2 089-2 119). La asociación de mayor fuerza con la mortalidad por diabetes se registró en la ciudad de México (RR 2,5; IC 2,33-2,68 en el 2000; RR 2,06; IC 1,95-2,18 en el 2007) y en la región socioeconómica 7 (RR 2,47; IC 2,36-2,57 en el 2000; RR 2,05; IC 1,98-2,13 en el 2007).

Conclusiones. Las tasas de mortalidad aumentaron de 77,9 a 89,2 por 100000 habitantes en el período 2000-2007 y fueron más altas entre las mujeres que entre los hombres. Las personas que no finalizaron la escuela primaria tuvieron un riesgo mayor de morir por diabetes (RR 2,104; IC 2,089-2,119). La entidad federativa de la ciudad de México y la región socioeconómica 7 presentaron la asociación de mayor fuerza con la mortalidad por diabetes.

Diabetes mellitus; mortalidad; clase social; México. 